\title{
SOME NEW CONCEPTS FOR ALL-OPTICAL 2R REGENERATION USING InP-BASED PHOTONIC INTEGRATED CIRCUITS
}

\author{
Jan De Merlier, Mingshan Zhao, Geert Morthier, Roel Baets \\ Department of Information Technology (INTEC), University of Gent-IMEC, Sint- \\ Pietersnieuwstraat 41, B-9000 Gent, Belgium. \\ ian.demerliereintec.rug.ac.be
}

\begin{abstract}
During the last years we have pioneered three new concepts for $2 \mathrm{R}$ optical regeneration. Two of these concepts, an active $2 \times 2$ multi mode interference (MMI) coupler and a Mach Zehnder interferometer with a regular semiconductor optical amplifier in one arm and an active 1X1 MMI in the other arm, have been fabricated as photonic integrated circuits. A third regenerator, a Mach-Zehnder interferometer with Gain-Clamped Semiconductor Optical Amplifiers (GCSOA's) in both arms, can in principle also be fabricated as a photonic integrated circuit, but has been implemented using a fiber interferometer and commercial GCSOA's. An extinction ratio improvement of around $15 \mathrm{~dB}$ as well as noise reduction has been demonstrated with all 3 concepts. In addition, one of the concepts has been demonstrated at $10 \mathrm{~Gb} / \mathrm{s}$.
\end{abstract}

Key words: Optical signal degradation, regeneration, interferometer

\section{INTRODUCTION}

Signals propagating over optical fiber networks are significantly distorted due to several causes such as fiber dispersion, noise accumulation in optical amplifiers and crosstalk addition in switches. This is especially the case in advanced WDM-based networks, where many channels at different wavelengths and each carrying signals of up to $40 \mathrm{~Gb} / \mathrm{s}$ are sent through long stretches of fiber and are traversing several optical amplifiers and optical switches. The resulting deterioration of the signals may require that signals are regenerated at intermediate nodes. This regeneration can be either $2 \mathrm{R}$ 
regeneration, consisting of signal reshaping, or $3 \mathrm{R}$ regeneration, consisting of signal reshaping and retiming. Although $3 \mathrm{R}$ regeneration will be required in most cases, $2 \mathrm{R}$ regeneration may be useful in parts of an optical network. Moreover, a $2 \mathrm{R}$ regenerator is itself an indispensable part of a $3 \mathrm{R}$ regenerator.

Although regeneration is perfectly possible using opto-electronic conversion, all-optical regeneration has many advantages, e.g. in terms of cost and power consumption, particularly as bitrates increase or if multi channel regeneration is required [1]. Many different solutions have already been proposed (cf. [2-6]) and they are either based on fiber loops [5,6] or on photonic integrated circuits [2-4]. The regenerators based on fiber loops are generally less stable and require polarisation control. However, all the optical $2 \mathrm{R}$ regenerators proposed so far have the disadvantage that they are either requiring an external pump signal, giving a poor regeneration or requiring a complex interferometric structure. Some alternative $2 R$ regenerator structures have been devised at the Department of Information Technology of Ghent University. These concepts, as well as experimental results obtained with them, will be discussed below.

\section{INTERFEROMETER WITH GAIN-CLAMPED SEMICONDUCTOR OPTICAL AMPLIFIERS (GCSOA's)}

A first concept for a $2 \mathrm{R}$ optical regenerator is a Mach-Zehnder interferometer (MZI) with equal GCSOA's in each arm, as depicted in Figure 1. The operation of this regenerator is based on the specific property of a GCSOA that its amplification in the linear regime is independent of the injected current, whereas the saturation power increases linearly with the injected current [5]. The two GCSOA's in Figure 1 are identical but are fed different bias currents such that they provide the same amplification in the linear regime but exhibit a different saturation in- and output power. For input powers below the saturation power of both GCSOA's, the equal gain in both arms and the phase difference of $\pi$ between both arms result in a complete destructive interference and a very low output power. Beyond the saturation power of both GCSOA's, both arms provide a constant (input power independent) output power, which is however different for both arms. In this region, both amplifers also cause a different phase shift. The resulting phase difference between both arms is still constant, but now different from $\pi$. As a result of the different phase shift and the different output power from 
both GCSOA's, a constant and relatively large output power is obtained at the output of the interferometer.

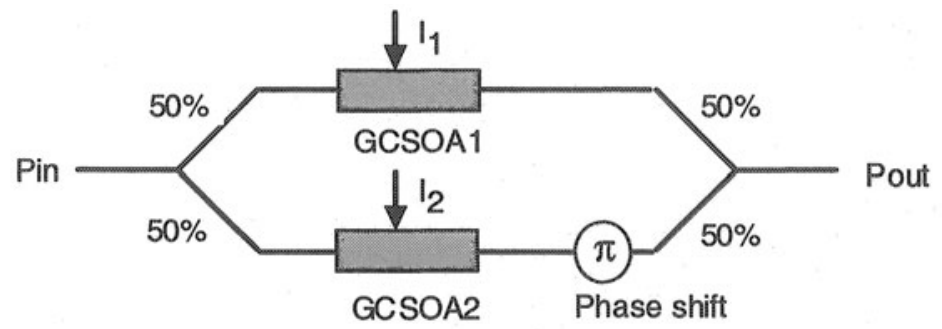

Figure 1.Regenerator based on a MZI with GCSOAs

This interferometer has been assembled using optical fiber and commercial, packaged GCSOAs. Both GCSOAs were not exactly identical and an equal gain in both arms was obtained using an additional variable optical attenuator. The phase difference of $\pi$ in the linear regime was assured using the temperature control of one of the GCSOAs. Figure 2 shows the measured output vs. input power under static operation conditions. A decision characteristic with a very sharp transition between the digital ' 0 ' and ' 1 ' and with good noise reduction in both the ' 0 ' and the ' 1 ' region is obtained. In fact, an extinction ratio of $1 \mathrm{~dB}$ at the input can be converted into an extinction ratio of $15 \mathrm{~dB}$ at the output. Moreover, the decision level can be adjusted through the bias currents to both GCSOAs and the regeneration is obtained over a broad wavelength range of $20 \mathrm{~nm}$.

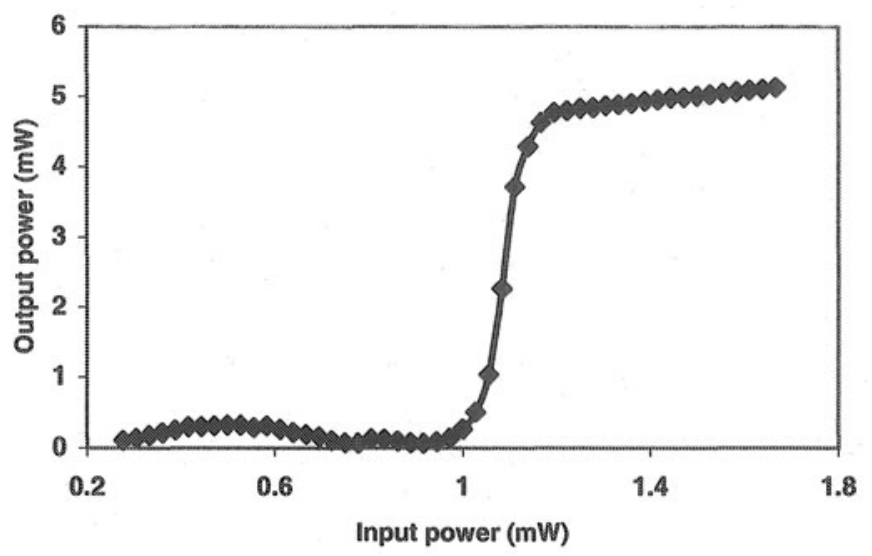

Figure 2. Experimentally measured characteristics of the regenerator from Figure 1. 
This regenerator can in principle be fabricated as a photonic integrated circuit. In addition, it is possible to design the GCSOA's for operation at very high speeds or use the recently introduced LOA's [6] instead of the GCSOA's for high speed operation.

\section{ALL-ACTIVE MULTI MODE INTERFERENCE (MMI) COUPLER}

We have also studied simpler layouts for optical $2 \mathrm{R}$ regenerators: an active $2 \times 2$ multi mode interference coupler (an MMI-SOA) and a Mach Zehnder interferometer with a regular SOA in one arm and a 1x1 MMI-SOA in the other arm. Both devices have been fabricated as an InP photonic integrated circuit at INTEC and have shown potential for regeneration with a significant extinction ratio improvement. Figure 3 explains the operation principle of the $2 \times 2$ MMI-SOA, which is based on modification of the interference between waveguide modes in the MMI. The length of the device is chosen such that the different waveguide modes interfere destructively in the bar state output waveguide at low input powers. However, as the input power increases, the carrier density is depleted, the refractive index profile in the waveguide is modified and so is the interference between the waveguide modes. At large input powers, the interference is no longer destructive but constructive. Figure 4 shows a photograph of a chip containing 4 of these $2 \times 2$ MMI-SOA. The MMI has a width of $8 \mu \mathrm{m}$ and a length of $580 \mu \mathrm{m}$ and the in- and output waveguides are $3 \mu \mathrm{m}$ wide. The active layer consists of eight $8 \mathrm{~nm}$ thick $1 \%$ compressively strained InGaAsP (Q1.65) quantum wells with InGaAsP (Q1.25) barriers of $15 \mathrm{~nm}$, sandwiched between two InGaAsP (Q1.25) layers of $90 \mathrm{~nm}$.

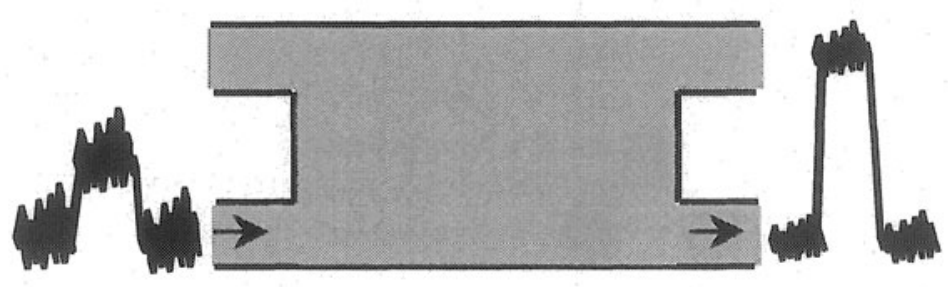

Figure 3. Principle of the MMI-SOA based regenerator 


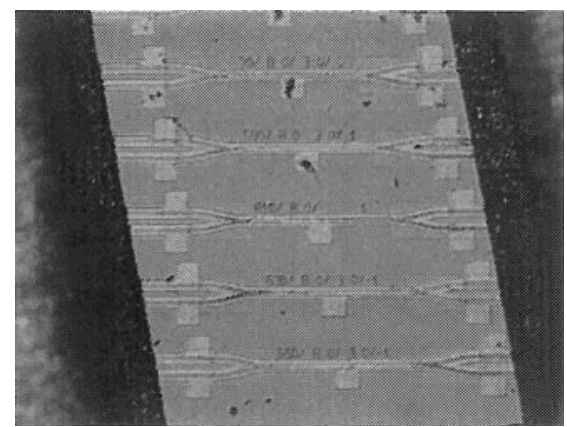

Figure 4. Photograph of the MMI-SOA based regenerator.

Figure 5 shows the regeneration characteristic measured for this device. Experimentally an output extinction ratio as high as $25 \mathrm{~dB}$ has been obtained for an input extinction ratio of $10 \mathrm{~dB}$ [7]. From Figure 5 one can also see that the decision point can be changed by changing the injected currents. In collaboration with Research Center COM from Denmark, this device has been used to demonstrate regeneration at $10 \mathrm{~Gb} / \mathrm{s}$ for a $\mathrm{RZ}$ bit pattern [8].

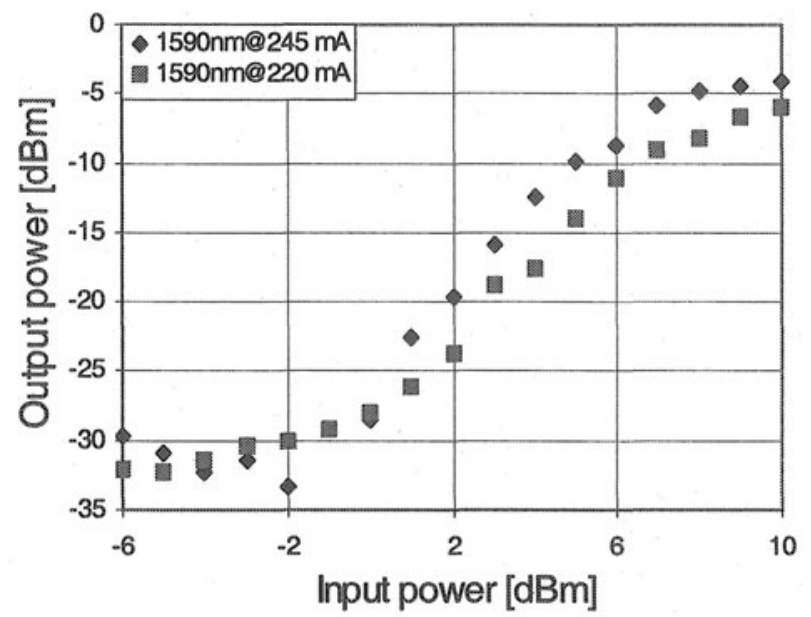

Figure 5. Experimental characteristic of the MMI-SOA based regenerator. 


\section{MZI WITH AN SOA IN ONE ARM AND AN MMI- SOA IN THE OTHER ARM}

The layout of this regenerator is shown in Figure 6. The SOA in one arm is replaced by a one-by-one MMI-SOA which images the input field from input to output waveguide. In the linear regime, one can again obtain an equal gain in both arms by providing the necessary current densities. If furthermore the additional phase shift $\phi$ is chosen such that the interference between both arms is destructive, a very low output power at the interferometer output is obtained in the linear regime. When the input power is increased, the SOAs in both arms saturate. However, the MMI-SOA has a larger (in-and output) saturation power due to the larger effective area of the cross section. This implies also that the phase difference between both arms changes faster between $\pi$ and 0 than in the case with identical SOAs in both arms. As a result, a sharp transition from the ' 0 ' to the ' 1 '-level is found.

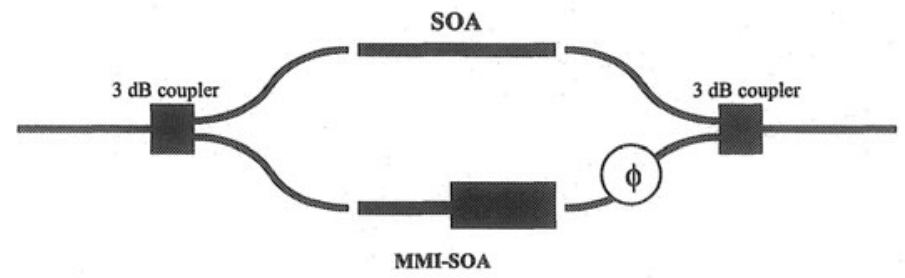

Figure 6. Layout of the MZI-based 2R regenerator incorporating an SOA and an MMI-SOA

Also this regenerator structure has been fabricated at INTEC and decision characteristics have been measured experimentally. In the fabricated device, the additional phase shifter $\phi$ has not been implemented and the phase difference of $\pi$ between both arms has to be achieved by adjustment of the currents in both arms. This obviously means that in reality is not possible to obtain simultaneously a phase difference of $\pi$ and equal gain in both arms. However, it turns out that, due to the asymmetry of the structure, it is possible to obtain a phase difference of $\pi$ with a relatively small difference in gain between both arms [9]. The experimental regeneration characteristic (shown in Figure 7) shows a large increase in extinction ratio, from $6 \mathrm{~dB}$ to over $20 \mathrm{~dB}$. The active layer structure for this device was the same as for the one described in the previous paragraph. The total arm length was $500 \mu \mathrm{m}$ and the one-by-one MMI had a length of $170 \mu \mathrm{m}$ and a width of $8 \mu \mathrm{m}$. 


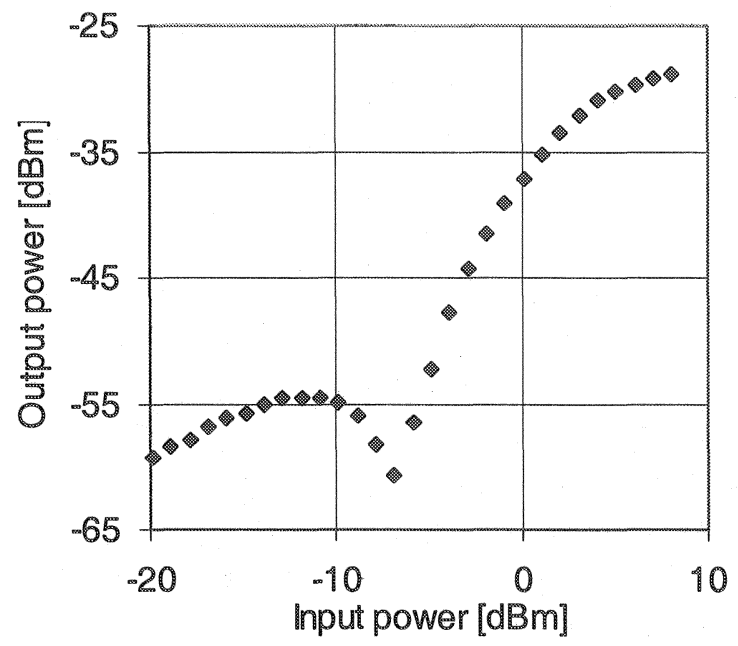

Figure 7. Measured regeneration characteristic of the regenerator from Figure 6.

\section{CONCLUSION}

We have briefly discussed a number of new concepts for $2 \mathrm{R}$ optical regeneration that have been proposed at INTEC and which have been either assembled or fabricated as well as measured at our department. All three concepts show advantages over other proposed regenerators, i.e. either simpler fabrication or better regeneration characteristics. The MZI with GCSOAs has superior regeneration characteristics, while the MMI-SOA and the MZI with one SOA and one MMI-SOA are easy to fabricate and small. Regeneration at $10 \mathrm{~Gb} / \mathrm{s}$ has been demonstrated using the MMI-SOA and potential for $10 \mathrm{~Gb} / \mathrm{s}$ operation is also expected from the other concepts.

\section{ACKNOWLEDGEMENT}

The authors wish to express their gratitude to S. Verstuyft, T. Van Caenegem, I. Moerman and P. Van Daele for their help with the fabrication of the monolithically integrated regenerators. Jan De Merlier acknowledges the IWT for financial support. 


\section{REFERENCES}

[1] B. Sartorius, '3R All-Optical Signal Regeneration', Proc. of 27th Eur. Conf. Opt. Comm. (ECOC'01), paper Tu.M.3.1, Amsterdam, October 2001.

[2] D. Wolfson, T. Fjelde, A. Kloch, C. Janz, A. Coquelin, I. Guillemot, F. Gaborit, F. Poingt, M. Renaud, 'Experimental Investigation at $10 \mathrm{~Gb} / \mathrm{s}$ of the Noise Suppression Capabilities in a Pass-Through Configuration in SOA-Based Interferometric Structures', Phot. Techn. Lett., Vol. 11, pp. 332-334, July 2000.

[3] J. Leuthold, B. Mikkelsen, R.E. Behringer, G. Raybon, C.H. Joyner, P.A. Besse, 'Novel 3R Regenerator Based on Semiconductor Optical Amplifier Delayed-Interference Configuration', Phot. Techn. Lett., Vol. 11, pp. 860-862, August 2000.

[4] B. Lavigne, D. Chiaroni, P. Guerber, L. Hamon, A. Jourdan, 'Improvement of regeneration capabilities in semiconductor optical amplifier-based 3R regenerator', Proc. of Optical Fiber Comms. Conf. 1999 (OFC'99), paper TuJ3, San Diego, 1999.

[5] 1. D. Philips, P. Gunning, A. D. Ellis, J. K. Lucek, D. G. Moodie, A. E. Kelly, D. Cotter, '10-Gb/s Asynchonous Digital Optical Regenerator', IEEE Phot. Techn. Lett., Vol. 11, pp. 892-894, 1999.

[6] H. J. Thiele, A. D. Ellis, I. D. Phillips, 'Recirculating loop demonstration of $40 \mathrm{Gbit} / \mathrm{s}$ alloptical $3 R$ data regeneration using a semiconductor nonlinear interferometer', Electr. Lett., Vol. 35, pp. 230-231, 1999.

[7] G. Morthier, M. Zhao, B. Vanderhaegen, R. Baets, 'Experimental Demonstration of an All-Optical 2R Regenerator with Adjustable Decision Threshold and 'true' Regeneration Characteristics', IEEE Phot. Techn. Lett., Vol. 12, pp. 1516-1518, November 2000.

[8] D. A. Francis S. P. DiJaili, J. D. Walker, 'A single-chip linear optical amplifier', Proc. of Optical Fiber Comms. Conf. 2000 (OFC'200), paper PD13, Anaheim, 2001.

[9] J. De Merlier, G. Morthier, T. Van Caenegem, R. Baets, I. Moerman, P. Van Daele, 'Experimental demonstration of $15 \mathrm{~dB}$ extinction ratio improvement in a new $2 \mathrm{R}$ optical regenerator based on an MMI-SOA', 27 th Eur. Conference on Optical Communication (ECOC'2001), Amsterdam, September 2001.

[10] M. L. Nielsen, J. De Merlier, G. Morthier, R. Baets, 'Experimental demonstration of alloptical $2 \mathrm{R}$ regeneration at $10 \mathrm{~Gb} / \mathrm{s}$ in a novel MMI-SOA based device', submitted to OFC'2002.

[11] J. De Merlier, G. Morthier, S. Verstuyft, T. Van Caenegem, I. Moerman, P. Van Daele, R. Baets, 'A novel 2R regenerator based on an asymmetric Mach-Zehnder interferometer incorporating an MMI-SOA', Annual Meeting IEEE-LEOS, San Diego, November 2001. 